\title{
Capsule Commentary on Davis et al., Improving Mammography Screening among the Medically Underserved
}

\author{
Judith Lee Smith, PhD \\ Centers for Disease Control and Prevention, Atlanta, GA, USA.
}

J Gen Intern Med 29(4):652

DOI: $10.1007 / \mathrm{s} 11606-013-2761-1$

(c) Society of General Internal Medicine 2014

$\mathrm{D}$ avis et al. ${ }^{1}$ report on the effectiveness and costeffectiveness of approaches to increase mammography screening among 1,181 women in Federally Qualified Health Centers (FQHCs) in Louisiana. The three arms evaluated were enhanced usual care (i.e., recommendation for and scheduling of mammogram), health literacy informed education (i.e., enhanced usual care plus educational materials), and health literary+nurse support (i.e., health literacy informed education plus nurse navigation). While all significantly increased mammography screening rates over baseline, the health literacy+nurse support arm was the most effective. Surprisingly, health literacy informed education was less effective than enhanced usual care, leading the authors to speculate that education to increase knowledge and awareness about breast cancer and mammography may not be necessary in this population, many of whom had previously received a mammogram. An important strength of this study is the inclusion of a cost-effectiveness analysis.

The Community Preventive Services Task Force has identified types of interventions that successfully increase mammography screening. ${ }^{2}$ Previous research has demonstrated that women reporting a provider recommendation were significantly more likely to receive a mammogram. ${ }^{3}$ Further, studies suggest that patient navigation facilitates mammography screening, particularly among the traditionally medically underserved. ${ }^{4}$

To increase the application of this work, there may be opportunities for public health entities to implement innovative approaches to identify women who need screening services, encourage participation, and monitor results. ${ }^{5} \mathrm{Im}$ portantly, the authors note that the nurse support arm may not be feasible for lower resource clinics. The navigation activities described in this study may be successfully completed by lay and other health professionals at lower cost. Caution is warranted before determining that women do not still require education to increase knowledge and awareness about screening mammography - the need for education may vary by the population being served.

Additional research is needed to identify and monitor additional barriers and facilitators to receipt of routine screening in this population, determine the individual-level and system-level characteristics of effective patient navigation programs, and demonstrate how electronic medical records can be used more effectively to track patients in safety-net clinics, hospitals, and systems.

Conflict of Interest: The author has no conflicts of interest with the material in this article.

Disclaimer: The findings and conclusions in this report are those of the author and do not necessarily represent the official position of the Centers for Disease Control and Prevention.

Corresponding Author: Judith Lee Smith, PhD; Centers for Disease Control and Prevention, Atlanta, GA 30341, USA (e-mail: JLeeSmith@cdc.gov).

\section{REFERENCES}

1. Davis TC, Rademaker A, Bennett C, Wolf MS, Carias E, Reynolds C, Liu D, Arnold CL. Improving mammography screening among the medically underserved. J Gen Intern Med. 10.1007/s11606-013-2743-3.

2. Guide to Community Preventive Services. Cancer prevention and control: client-oriented and provider-oriented screening interventions. http:// www.thecommunityguide.org/cancer/screening/client-oriented/ index.html and http://www.thecommunityguide.org/cancer/screening/ provider-oriented/index.html. Accessed 9 December 2013.

3. O'Malley MS, Earp JA, Hawley ST, Schell MJ, Mathews HF, Mitchell J. The association of race/ethnicity, socioeconomic status, and physician recommendation for mammography: who gets the message about breast cancer screening? Am J Public Health. 2001;91(1):49-54.

4. Earp JA, Eng E, O'Malley MS, Altpeter M, Rauscher G, Mayne L, Mathews HF, Lynch KS, Gaqish B. Increasing use of mammography among older, rural African American women: results from a community trial. Am J Public Health. 2002;92(4):646-54.

5. Plescia M, White MC. The National Prevention Strategy and breast cancer screening: scientific evidence for public health action. Am J Public Health. 2013;103(9):1545-8. Epub 2013 Jul 18.

Published online January 24, 2014 